\title{
Review
}

\section{Robotics in Gastrointestinal Endoscopy}

\author{
Sang-Hyun Kim, Hyuk-Soon Choi *, Bora Keum and Hoon-Jai Chun
}

check for

updates

Citation: Kim, S.-H.; Choi, H.-S.; Keum, B.; Chun, H.-J. Robotics in Gastrointestinal Endoscopy. Appl. Sci. 2021, 11, 11351. https://doi.org/ 10.3390/app112311351

Academic Editor: Byung-Ju Yi

Received: 14 October 2021

Accepted: 25 November 2021

Published: 30 November 2021

Publisher's Note: MDPI stays neutral with regard to jurisdictional claims in published maps and institutional affiliations.

Copyright: (c) 2021 by the authors. Licensee MDPI, Basel, Switzerland. This article is an open access article distributed under the terms and conditions of the Creative Commons Attribution (CC BY) license (https:/ / creativecommons.org/licenses/by/ $4.0 /)$.
Division of Gastroenterology and Hepatology, Department of Internal Medicine, Korea University College of Medicine, Seoul 136-701, Korea; snell17@korea.ac.kr (S.-H.K.); borakeum@korea.ac.kr (B.K.); drchunhj@korea.ac.kr (H.-J.C.)

* Correspondence: mdkorea@korea.ac.kr; Tel.: +82-10-4909-0079; Fax: +82-2-953-1943

\begin{abstract}
Recent advances in endoscopic technology allow clinicians to not only detect digestive diseases early, but also provide appropriate treatment. The development of various therapeutic endoscopic technologies has changed the paradigm in the treatment of gastrointestinal diseases, contributing greatly to improving the quality of life of patients. The application of robotics for gastrointestinal endoscopy improves the maneuverability and therapeutic ability of gastrointestinal endoscopists, but there are still technical limitations. With the development of minimally invasive endoscopic treatment, clinicians need more sophisticated and precise endoscopic instruments. Novel robotic systems are being developed for application in various clinical fields, to ultimately develop into minimally invasive robotic surgery to lower the risk to patients. Robots for endoscopic submucosal dissection, autonomous locomotive robotic colonoscopes, and robotic capsule endoscopes are currently being developed. In this review, the most recently developed innovative endoscopic robots were evaluated according to their operating mechanisms and purpose of use. Robotic endoscopy is an innovative treatment platform for future digestive endoscopy.
\end{abstract}

Keywords: robotic endoscopy; robotic endoscopy platforms; endoscopic submucosal dissection; colonoscopy

\section{Introduction}

After the invention of the first flexible fiberoptic gastroscope in 1957 [1], the role of endoscopy in the field of gastroenterology has developed remarkably. With the spread and development of endoscopes, it has become possible to accurately diagnose and treat digestive diseases at an early stage. The evolution of the endoscopic device itself has reached its limitations, and various robotic endoscopes are being developed to perform advanced procedures. The main fields of interest in which robotic endoscopy is being developed are endoscopic submucosal dissection (ESD) and colonoscopy [2]. Significant progress has been made in the fields of ESD and colonoscopy, and recently, various diagnostic and therapeutic devices using artificial intelligence (AI) have been developed [3].

ESD was introduced by Japanese physicians in the 1990s for radical resection of early gastric cancer, which was a revolution in therapeutic endoscopy [4]. With the development of ESD, en bloc resection has become possible regardless of the size, location, and shape of the gastrointestinal tumor. However, there are several unique technical difficulties in performing ESD. Effective traction of dissected flap for visualizing the dissection plane in ESD is difficult to achieve using a conventional endoscope [5]. As the instruments are inserted parallel to the axis of the endoscope, off-axis movements such as triangulation of instruments are almost impossible [6]. Because of the instability of flexible endoscopy, it is also difficult to accurately transmit the force from the endoscopist to the surgical field. As the surgical instrument and the endoscopic camera are on the same plane, the visual field continues to change whenever the endoscope moves for surgery, making the procedure difficult [7]. It takes a considerable amount of learning to be proficient in ESD procedures [8]. As interest in natural orifice translumenal surgery (NOTES) increases, vari- 
ous robotic endoscopy platforms are being developed to overcome the technical limitations of conventional endoscopes.

Robotic devices are also being developed to assist in safe and effective colonoscopies. Colonoscopy can potentially be more technically demanding than gastroscopy, as the colon is a long, tortuous, thin-walled organ that has multiple haustrations. Patient complications, patient sedation, and difficult location in the colon can make therapeutic procedures in colon very difficult. Robotic assisted colonoscopy aims to improve the patient's tolerance, facilitate cecal intubation regardless of the endoscopist's ability, and perform therapy safely.

Various robotic endoscopic devices have been described in the literature over the past decade. Some of them were tested in preclinical and clinical settings, and some projects appeared to have been discontinued. In this review, we introduce three major categories of robotic endoscopy. The first category is robot-assisted therapeutic devices that assist advanced endoscopic procedures, such as ESD. This category includes robotic endoscopic multitasking platforms and robotic add-on devices. The second category is the robotassisted colonoscopy system. A robotic-driven colonoscope that automatically navigates in the colon and an auxiliary device that assists the conventional colonoscope are in this category. The last category is a robotic capsule endoscopy.

A literature review was performed on PubMed and Web of Science databases by search criteria "robotic ESD" OR "robot" AND "endoscopy" OR "endoscopy robots" OR "robotic platform" AND "endoscopy" OR "robot" AND "colonoscopy" OR "flexible endoscopic multitasking platforms" OR "robot" AND "capsule endoscopy" and specific names of various robotic endoscopic multitasking platforms and robotic colonoscopy systems from 1 January 2010 to 31 December 2020. Relevant articles pertaining to robotic flexible gastrointestinal endoscopy are identified from title and abstract. In addition, important references were identified through individual article references. The content presented in related journals published by the Institute of Electrical and Electronics Engineers (IEEE) in the same period was also reviewed. The innovative and clinically tested products over the past 5 years in the IEEE database were reviewed and are detailed in the review below.

\section{Review of Robot Assisted Endoscopic Devices (Robot Assisted ESD System)}

\subsection{Robotic Endoscopic Multitasking Platform}

The robotic endoscopic multitasking platform has been developed to address triangulation and optimal tissue counter-traction, which are the biggest obstacles to the conventional endoscope performing complex procedures. Most robotic endoscopy platforms come with an operator console and a flexible endoscope with at least two multi-articular actuated arms to perform precise manipulation of tissues [7]. Those devices follow the master-slave robotic concept and are designed for telemanipulation (Table 1). The basic concept of this robotic platform is to hold the ESD flap with the articulating end effector and proceed with dissection with the other end effector. This is similar to the surgical robots for NOTES such as the da Vinci Surgical System (Intuitive Surgical, Sunnyvale, CA, USA). Robot-assisted ESD increases the degree of freedom of the robot arm, thus improving the maneuverability [9]. Through the robotic platform, the endoscopist's external movement is scaled down and converted into an accurate internal movement, allowing an accurate and safe ESD procedure. However, these systems have the disadvantages of being large, complex, expensive, and cumbersome because they require docking/registering and undocking the system for the procedure. There are also many cables connected inside the robotic endoscope, resulting in a significant level of hysteresis that causes "delayed behavior" in the surgical field [7]. The leaders in the robotic endoscopic multitasking platform that can perform precise procedures despite these technical difficulties are Endomaster EASE System and Endoluminal Assistant for Surgical Endoscopy [10]. 
Table 1. Summary table of robotic endoscopic multitasking platforms.

\begin{tabular}{|c|c|c|c|c|}
\hline Name & Approval Status & Clinical Trial & Purpose of Use & Technical Features \\
\hline $\begin{array}{c}\text { Endomaster EASE System } \\
\text { (EndoMASTER Pte., } \\
\text { Singapore) }\end{array}$ & No & $\begin{array}{l}\text { Animal } \\
\text { Human }\end{array}$ & $\begin{array}{l}\text { Stomach ESD } \\
\text { Colon ESD }\end{array}$ & $\begin{array}{l}\text { Console for remote control of the } \\
\text { robotic arms, Independent } \\
\text { endoscopic platform }\end{array}$ \\
\hline $\begin{array}{l}\text { Endoluminal Assistant for } \\
\text { Surgical Endoscopy } \\
\text { (ICube Laboratory, } \\
\text { Strasbourg, France) }\end{array}$ & No & Animal & Colon ESD & $\begin{array}{l}\text { Master console and a detachable } \\
\text { flexible endoscope with three } \\
\text { working channels }\end{array}$ \\
\hline $\begin{array}{c}\text { Flex Robotic System } \\
\text { (Medrobotics, Raynham, } \\
\text { MA, USA) }\end{array}$ & FDA & $\begin{array}{l}\text { Animal } \\
\text { Human }\end{array}$ & Colon ESD & $\begin{array}{l}\text { Robotic endoscope, mechanical } \\
\text { single-use flexible instruments } \\
\text { and a master console with a } \\
\text { touchscreen, HD visual display, } \\
\text { a joystick }\end{array}$ \\
\hline $\begin{array}{c}\text { K-FLEX } \\
\text { (EasyEndo Surgical, } \\
\text { Daejeon, Korea) }\end{array}$ & No & $\begin{array}{l}\text { Explanted animal } \\
\text { organs }\end{array}$ & Colon ESD & $\begin{array}{l}\text { Bendable overtube, two } \\
\text { exchangeable surgical } \\
\text { instrument modules, a driving } \\
\text { robot arm and a master console }\end{array}$ \\
\hline
\end{tabular}

\subsubsection{Endomaster EASE System (EndoMaster Pte. Ltd., Singapore)}

The Endomaster EASE System (EndoMaster Pte. Ltd., Singapore), formerly known as the master and slave transendoluminal robot (MASTER), is a newly designed flexible robotic endoscopy platform for ESD. The system consisted of a console for remote control of the robotic arms and an independent endoscopic platform (Figure 1) [11]. The endoscopic platform has three working channels: two for the robotic arms and one for therapeutic accessories. The robotic arm was telemanipulated by a surgeon manipulating the controller of the console. Two robotic arms performed retraction and dissection with nine degrees of freedom; the left arm was designed for retraction and the right arm for dissection. Initial animal studies showed success in gastric full-thickness resection, hepatic wedge resection, stomach ESD, and colorectal ESD [12-14]. In a human feasibility study, successful gastric and colon ESD was performed $[11,15]$. The Endomaster platform currently has no CE or FDA approval.

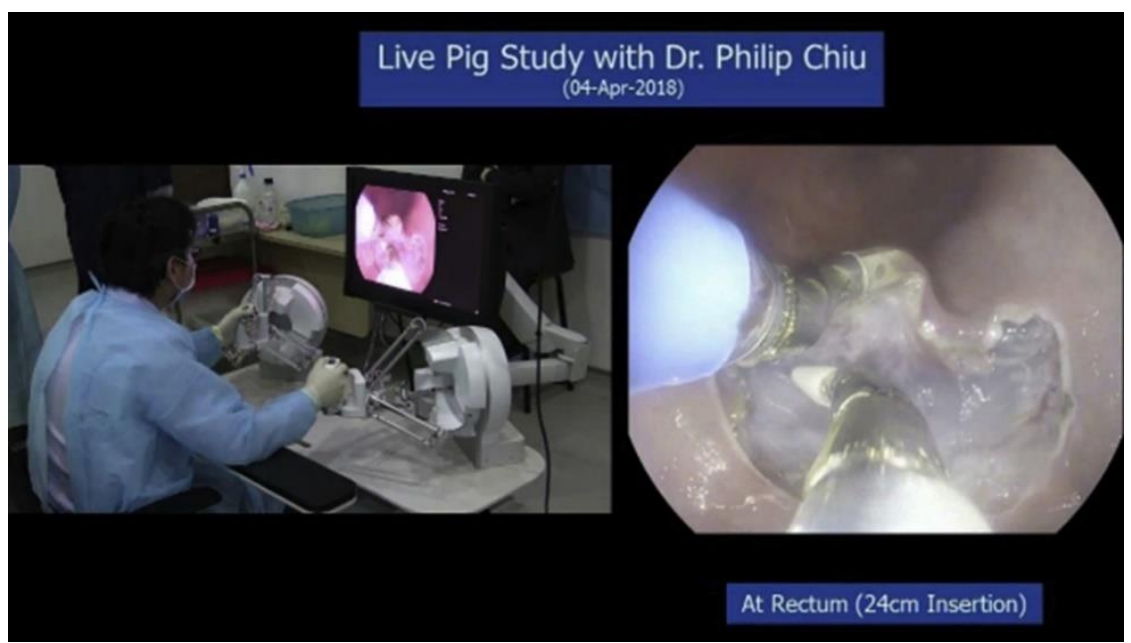

Figure 1. Endomaster EASE System (EndoMASTER Pte, Singapore) [11]. Colonic endoscopic submucosal dissection performed using the latest version of the EndoMaster EASE System. Robotic ESD was performed by grasping the mucosa with the robotic grasper and dissecting the submucosal plane using the needle-type dissecting knife with electrocautery. 
2.1.2. Endoluminal Assistant for Surgical Endoscopy (ICube Laboratory, Strasbourg, France)

The ISIS-Scope/STRAS System (Karl Storz, IRCAD, Tuttlingen, Germany) was developed as a remotely operated robotized platform of manual Anubiscope (Karl Storz) [16,17]. The Endoluminal Assistant for Surgical Endoscopy (EASE) is the latest version of STRAS. EASE is a platform composed of the master and slave units (Figure 2) [17]. The slave unit consists of a mobile master console and a detachable endoscope. The 53.5- $\mathrm{cm}-\mathrm{long}$ detachable endoscope has two $4.3 \mathrm{~mm}$ side working channels for the platform's unique robotic instruments and a $3.2 \mathrm{~mm}$ central working channel for conventional endoscopic instruments. This platform provides 10 degrees of freedom. The surgeon at the master console unit can control both the endoscope and instruments. The surgeon has two screens: a frontal view with an endoscopic view and a graphically reconstructed view with a user interface that maps the positions of the endoscope and instruments. The master controller consists of joysticks and four-way thumb switches to control endoscope movements. EASE is designed for use in lower gastrointestinal procedures and has reported 12 successful ESDs for large lesions in porcine colon models [16]. A recent small trial showed that the dissection speed gap between novices and experts was reduced when using EASE for ESD and showed a shorter learning curve for novices [17]. This platform currently has no CE or FDA approval.

A

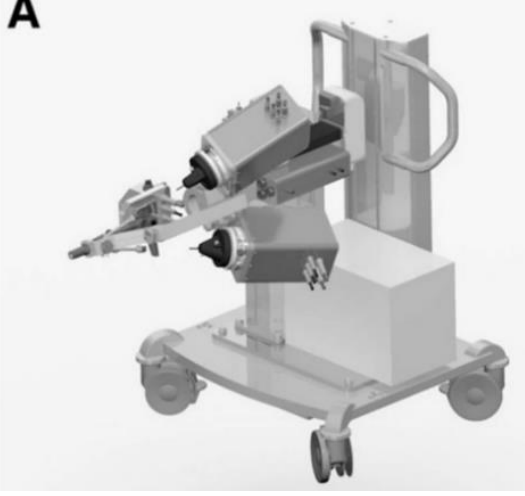

B

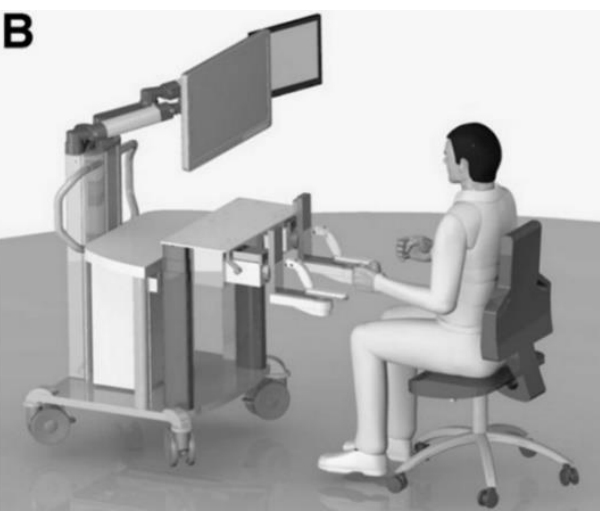

Figure 2. Virtual rendering of Endoluminal Assistant for Surgical Endoscopy. (A) Slave unit: mobile cart with robotic modules. (B) Master unit [17]. The ergonomic design of the master unit allows a single operator sitting at the console to control both the endoscope and the instruments.

\subsubsection{Flex Robotic System (Medrobotics, Raynham, MA, USA)}

The Flex Robotic System (Medrobotics, Raynham, MA, USA) is a robotic platform for lower GI tract procedures. It is composed of a robotic endoscope, mechanical single-use flexible instruments, a master console, an HD screen, and a joystick (Figure 3) [18]. This system was originally developed for head and neck surgery [19], but has been recently modified to perform procedures in the lower GI tract. The scope has two working channels and can accommodate several therapeutic accessories. The robot can access the lesions up to $25 \mathrm{~cm}$ from the anal verge. The robotic endoscope is controlled by an operator at the master console. This device provides dual manual control, which makes it easy to use two instruments. In an ex vivo porcine colon model experiments, when using FLEX, ESD novices performed ESD faster and safer than using conventional ESD methods [18]. This system was approved by the FDA for lower GI tract procedures in 2017. 


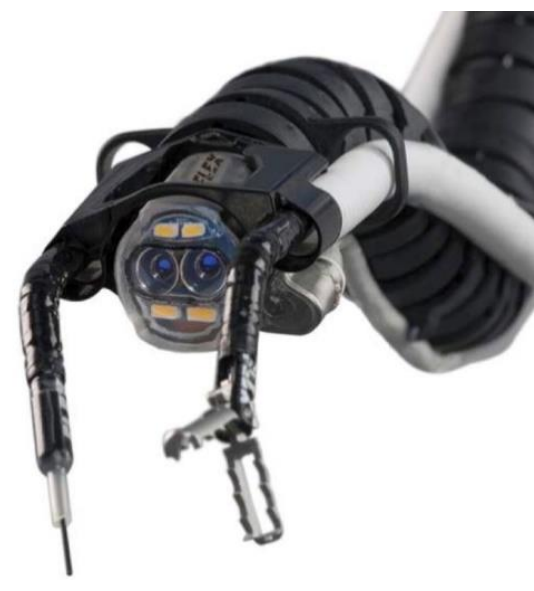

(a)

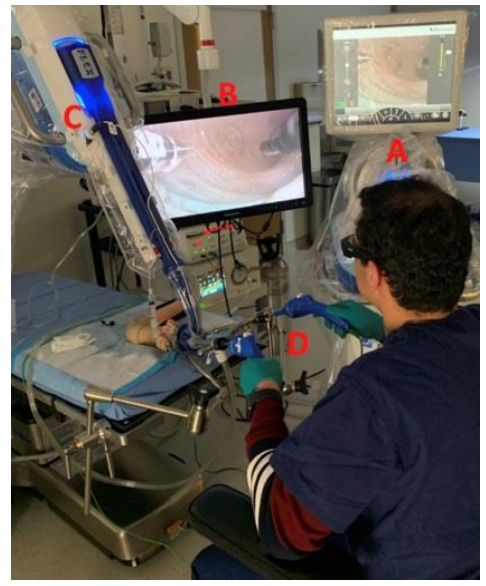

(b)

Figure 3. Flex Robotic System (Medrobotics, Raynham, MA, USA) [18]. (a) The robot's flexible distal end including two working channels with a needle-knife and grasper. (b) Performing ESD with the robotic system using three-dimensional high-definition visualization. A-Console with the physician controller. B-3-Dimensional high-definition monitor. C-Base and drive of the robot. D-Instrument support assembly.

\subsubsection{K-FLEX (EasyEndo Surgical, Daejeon, Korea)}

The K-FLEX (EasyEndo Surgical, Daejeon, Korea) is a robotic endoscopic platform for advanced endoluminal surgery. The platform is composed of a bendable overtube, two exchangeable surgical instrument modules, a driving robot arm, and a master console (Figure 4) [20]. The motion of each robot arm was controlled to bend up and down, left, and right with an intuitive thumb stick. The robot arm allows two independent bends at an angle of more than $100^{\circ}$ in each direction, allowing multidirectional traction. The robot arm has a $2.8 \mathrm{~mm}$ working channel and a joint configuration that allows precise movement. The robot's left arm was equipped with a grasping end effector and the right arm with a monopolar cautery. The master console monitor has a graphic simulator showing approximate location of the robot arm in the GI tract. Ex vivo porcine stomach ESD experiments were successfully conducted [21]. CE or FDA approval was not obtained.

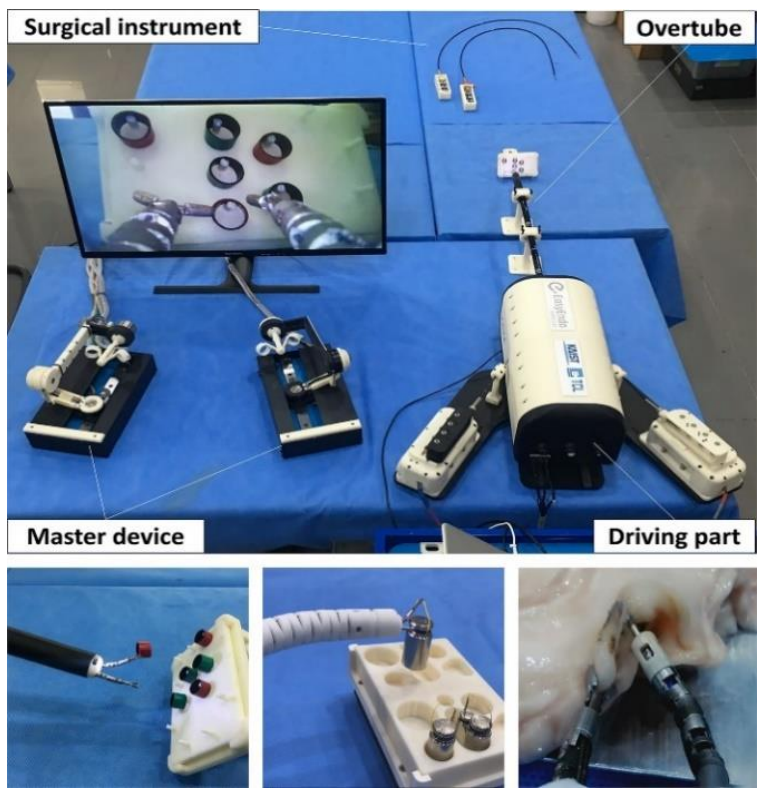

Figure 4. K-FLEX (EasyEndo Surgical, Daejeon, Korea). The K-FLEX system is composed of two surgical instruments, overtube, driving robot arm, and a master console [20]. 


\subsection{Robotic Add-On Devices}

Robotic add-on devices are attached to conventional endoscopes to improve visual fields and enhance distal dexterity while performing ESD. The advantages of robotic addon devices are that they are relatively inexpensive and easy to sterilize after use. They also minimize the disruption to current clinical workflows owing to the simple attachment and removal. These assistive robotic devices are expected to show greater improvements in surgical safety and dissection speed [22]. Because robotic add-on devices have limited functions, they are less capable of triangulation of instruments and tissue manipulation compared to the robotic endoscopic multitasking platform.

\subsubsection{ROSE (Endorobotics, Seoul, Korea)}

The ROSE (robot for surgical endoscope) platform is a surgical robot system that provides multi-directional traction during ESD. The ROSE consists of a robotic manipulator, an intuitive user interface (UI), and an actuation station (Figure 5) [23]. The robotic manipulator can be attached to the distal end of the conventional endoscope. Multidirectional traction with a robotic manipulator provides a clear visualization of the dissection plane. The robotic manipulator can bend up and down and move left and right along the tip of the endoscope. The endoscopist operates the robotic manipulator by controlling the UI attached to the control body of the endoscope. The operation of the ROSE is based on a tendon-sheath mechanism. In an in vivo porcine stomach experiment, ESD novices were able to successfully perform ESD with the ROSE [23]. CE or FDA approval was not obtained.

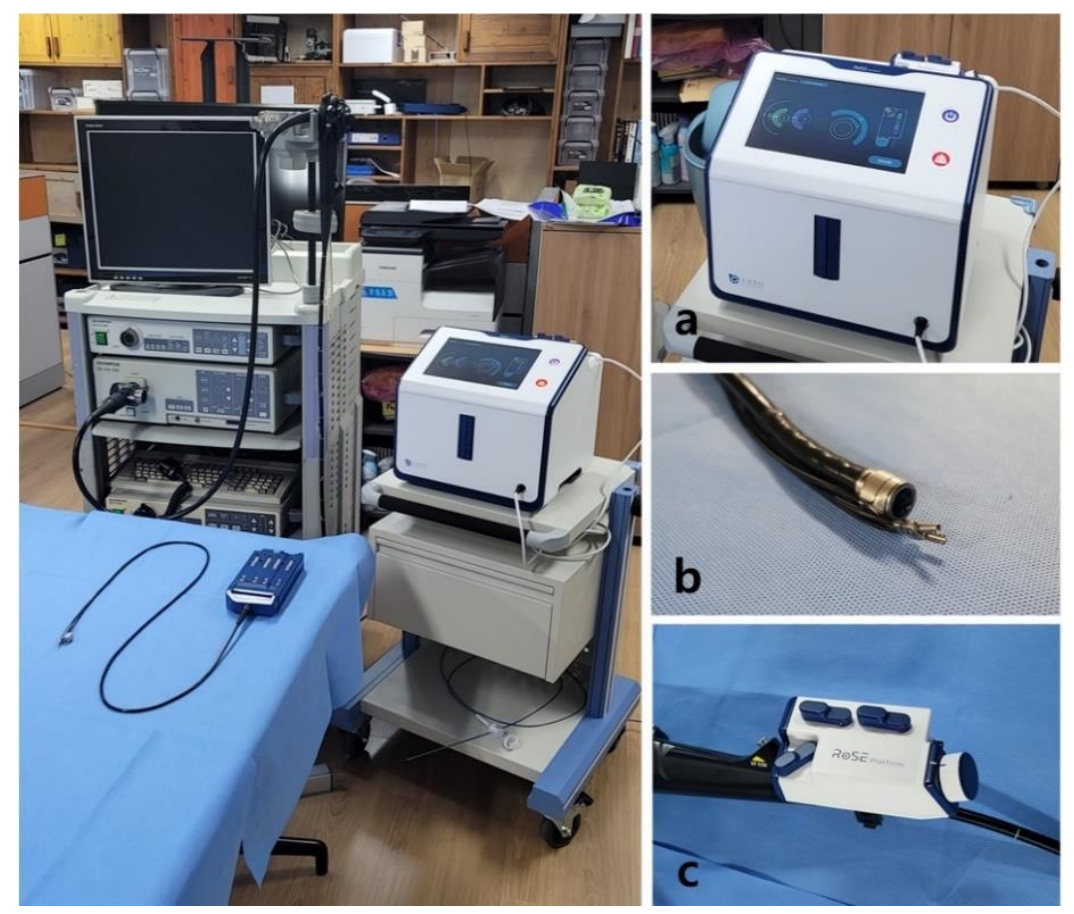

Figure 5. ROSE (Endorobotics, Seoul, Korea) (with permission from Endorobotics, Seoul, Korea). (a) Actuation station. (b) Robotic manipulator attached to the distal end of the conventional endoscope. (c) Intuitive user interface.

\subsubsection{EndoMODRA (Harvard University, Cambridge, MA, USA)}

EndoMODRA (endoscopic module for on-Demand robotic assistance) is a modular robotic system that can be attached to the distal end of conventional endoscope to give additional dexterity for horizontal motion. Because ESD requires the most dexterity when performing a series of lateral incisions along the submucosal plane, this robot was designed to provide additional dexterity for horizontal motion. EndoMODRA consists of a 
detachable distal robotic module with integrated actuation and sensing functions, which allows closed-loop control of therapeutic tools (Figure 6) [24]. EndoMODRA's robotic machine with a dissection knife moves left and right, performing a lateral sweeping motion, which can be automatically repeated through the sensors of the machine. Endoscopists can focus more on controlling the gross motion of the endoscope. In vivo porcine stomach ESD experiments were successfully conducted [24]. CE or FDA approval was not obtained.
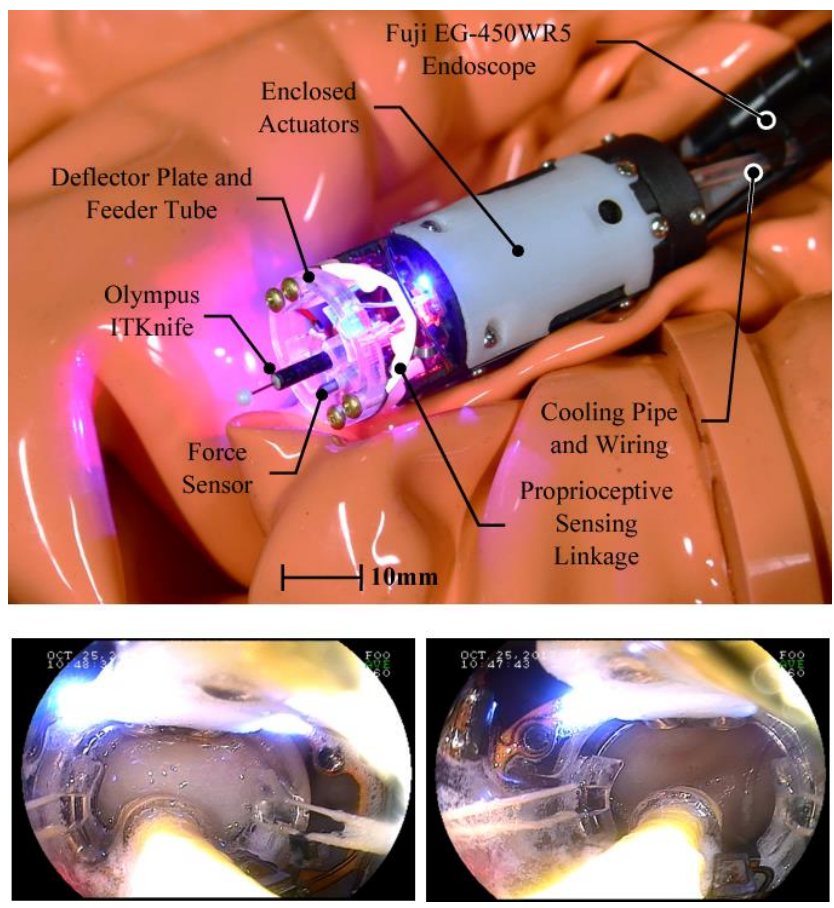

Figure 6. EndoMODRA (Harvard University, Cambridge, MA, USA) [24]. Image of a distallymounted robotic endoscopic module with integrated actuation and sensing. (Bottom) shows the view through the endoscope during an ex vivo dissection.

Robot Assisted Colonoscopy System

\subsection{Robotic-Driven Endoscope Locomotion}

Colonoscopy is a technically challenging procedure, as it is performed by manually pushing a semi-rigid endoscope through the tortuous colon lumen. Colonoscopy robots are being actively developed to reduce pain in patients, reduce the risk of perforation, and promote cecal intubation, regardless of the endoscopist's ability. Flexible self-propelled devices have been developed to reduce pain and discomfort during colonoscopy. They follow the loop smoothly without painful stretching the bowel, potentially avoiding the need for sedation. To reduce the risk of cross-infection, these endoscopes are being attempted to be single-use.

The currently developed autonomous colonoscopy robot can be classified as follows, based on the actuation principle (Table 2): (1) using electro-pneumatic mechanisms, that is, the Aer-O-Scope ${ }^{\mathrm{TM}}$ System, Endotics System, ColonoSight; (2) electromechanically actuated robotic colonoscopes, that is, the NeoGuide Endoscopy System, the Endoculus; (3) magnetic-actuated tethered robotic colonoscopes, that is, magnetic flexible endoscope, the Endoo EU project capsule. Products that have been commercialized are the Aer-OScopeTM System, Endotics System, ColonoSight, and the NeoGuide Endoscopy System. Endoculus, magnetic flexible endoscope and the Endoo EU project capsule are currently in the development stage. All commercialized products showed cecum intubation rate of over $90 \%$, however, none of these robotic endoscopes has entered clinical routine yet [25-28]. 
Table 2. Summary of the operating principles and technical features of the most recently developed robotic flexible colonoscopy systems.

\begin{tabular}{|c|c|c|c|c|}
\hline Name & Single Use & Approval Status & Actuation Principle & Technical Features \\
\hline $\begin{array}{c}\text { The Aer-O-ScopeTM Colonoscope } \\
\text { System } \\
\text { (GI View Ltd., Tel Aviv, Israel) }\end{array}$ & Yes & FDA, CE & $\begin{array}{l}\text { Electro-pneumatic } \\
\text { mechanisms }\end{array}$ & Self-propelled, disposable colonoscope \\
\hline $\begin{array}{c}\text { Endotics } \\
\text { (ERA Endoscopy SRL, Cascina, Italy) }\end{array}$ & Yes & $\mathrm{CE}$ & $\begin{array}{l}\text { Electro-pneumatic } \\
\text { mechanisms }\end{array}$ & $\begin{array}{l}\text { Self-propelled, joystick-controlled } \\
\text { endoscope }\end{array}$ \\
\hline $\begin{array}{c}\text { ColonoSight } \\
\text { (Stryker GI, Haifa, Israel) }\end{array}$ & Yes & FDA & $\begin{array}{l}\text { Electro-pneumatic } \\
\text { mechanisms }\end{array}$ & $\begin{array}{l}\text { Self-advancing system composed of a } \\
\text { reusable colonoscope and } \\
\text { a wrapped disposable multi-lumen } \\
\text { sheath }\end{array}$ \\
\hline $\begin{array}{l}\text { NeoGuide Endoscopy System } \\
\text { (Intuitive Surgical Inc., Sunnyvale, } \\
\text { CA, USA) }\end{array}$ & Yes & FDA & $\begin{array}{l}\text { Electro-mechanical } \\
\text { actuation }\end{array}$ & $\begin{array}{l}\text { 16-segment insertion tube that controls } \\
\text { the snake-like } \\
\text { movement of the endoscope }\end{array}$ \\
\hline $\begin{array}{c}\text { Endoculus } \\
\text { (University of Colorado, Boulder, } \\
\text { CO, USA) }\end{array}$ & No & No & $\begin{array}{l}\text { Electrically actuated } \\
\text { mechanisms }\end{array}$ & $\begin{array}{l}\text { Small tank-like robot that can navigate } \\
\text { the colon }\end{array}$ \\
\hline $\begin{array}{c}\text { Magnetic flexible endoscope } \\
\text { (Vanderbilt University, Nashville, } \\
\text { TN, USA) }\end{array}$ & No & No & $\begin{array}{l}\text { Magnetic-actuated } \\
\text { tethered robotic } \\
\text { colonoscopes }\end{array}$ & $\begin{array}{l}\text { Magnet-embedded endoscope, an } \\
\text { actuated permanent magnet external to } \\
\text { the patient, and a control software }\end{array}$ \\
\hline
\end{tabular}

\subsubsection{Aer-O-Scope ${ }^{\mathrm{TM}}$ Colonoscope System (GI View Ltd., Tel Aviv, Israel)}

The Aer-O-Scope ${ }^{\mathrm{TM}}$ Colonoscope System (GI View Ltd., Tel Aviv, Israel) is a selfpropelled disposable colonoscope. It has two contour-conforming balloons that help navigate the colon (Figure 7) [29]. One was placed at the anus, and inflated to block the air passage, and the other was located right behind the distal tip balloon. When the machine is inserted into the colon, the two contour-conforming balloons are insufflated to form an airtight seal, and $\mathrm{CO} 2$ is insufflated between them. A positive pressure gradient is generated from the distal colon, propelling the distal tip gently to the proximal colon. The advantage of this machine is that it is easy to operate even for beginners and the two cameras allow a $360^{\circ}$ panoramic view. Because the colonoscope is disposable, there is no risk of cross-contamination, and this helps avoid the costs associated with cleaning, pressurized storage, repair, or maintenance. Recently, Aer-O-Scope has added a therapeutic channel. The Aer-O-Scope has both FDA approval and the CE mark.
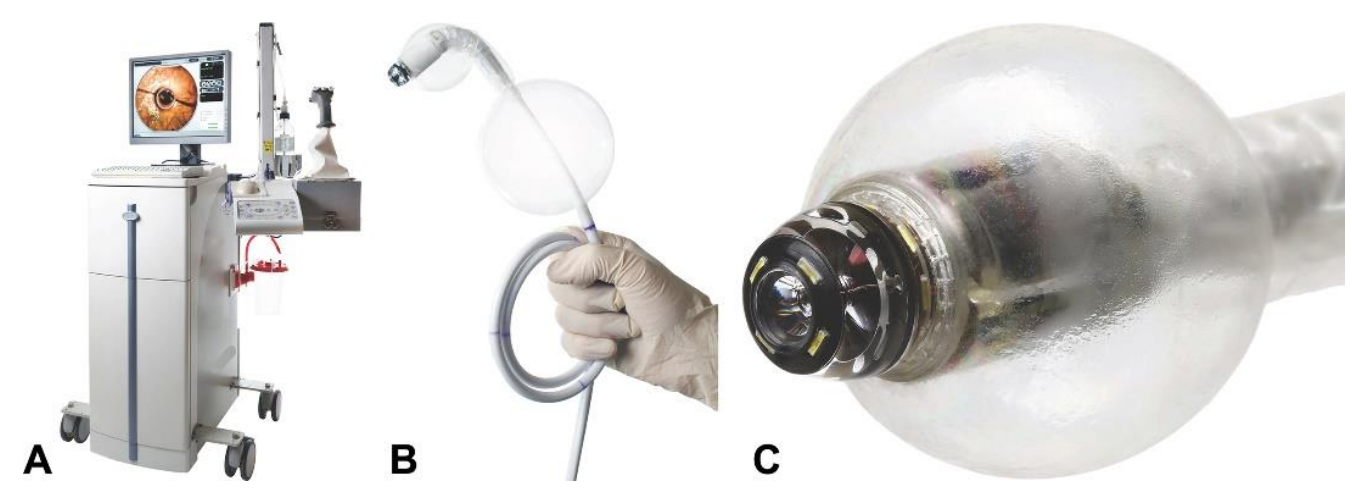

Figure 7. Features of the Aer-O-Scope TM Colonoscope System (GI View Ltd., Tel Aviv, Israel). (A) External workstation with full joystick control. (B) Disposable scanner unit comprising a soft, flexible cable attached to a system of polyurethane balloons. (C) Scanner tip with openings for irrigation, suction, and insufflation $[27,29]$.

\subsubsection{Endotics (ERA Endoscopy SRL, Cascina, Italy)}

Endotics (ERA Endoscopy) is a self-propelled, joystick-controlled endoscope. The probe was clamped onto the mucosa through vacuum and mechanical grasping. The 
concept of lengthening or shortening by moving forward through fixing the two anchor points used by this device is inspired by the movement of the inchworm (Figure 8) [30]. The ergonomic console allows clinicians to control the probe safely and painlessly. The system now has a $3 \mathrm{~mm}$ therapeutic tool channel. The Endotics system received CE-mark and is commercially available.

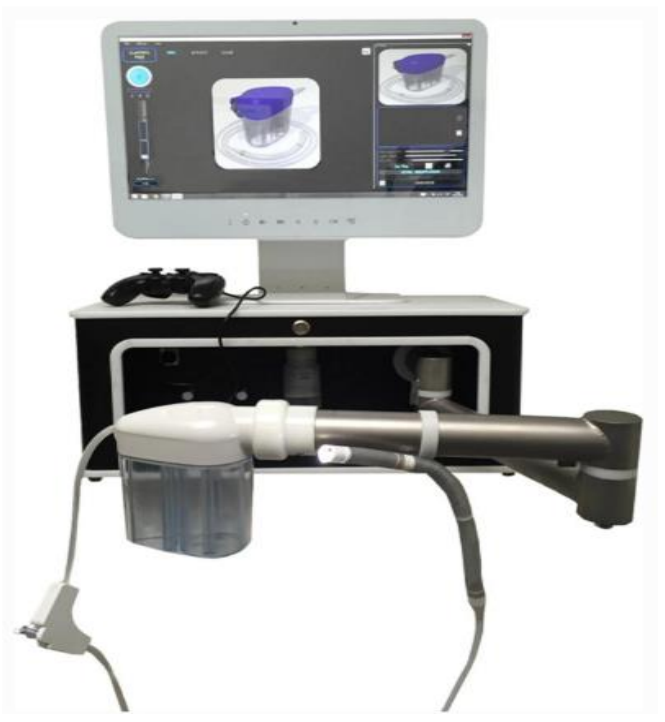

Figure 8. Endotics (ERA Endoscopy SRL, Cascina, Italy) (with permission from Endotics, http: //www.endotics.com/, 29 November 2021). The Endotics system is composed of a workstation and a hand-held console which drives a steerable probe through the colon lumen.

\subsubsection{ColonoSight (Stryker GI, Haifa, Israel)}

ColonoSight (Stryker GI Ltd., Haifa, Israel) is a self-advancing system composed of a colonoscope, covered by a wrapped disposable multilumen sheath to prevent the endoscope from contact with infectious agents. The device uses air pressure assisted pull technology [28]. As the protective disposable sheath is insufflated, the pneumatic mechanism creates a forward force below the tip of the endoscope. The forward force at the tip pulls the endoscope through the colon, thereby reducing the overall pushing force. This reusable colonoscope does not need disinfection procedure as a single-use sheath including the working channel prevents the endoscope from contamination.

\subsubsection{NeoGuide Endoscopy System (Intuitive Surgical Inc., Sunnyvale, CA, USA)}

The NeoGuide endoscopy system is a computer-assisted colonoscope designed to move along the natural curvature of the colon. There is a sensor on the tip to measure tip steering and an external position sensor to measure insertion depth [31]. It consists of multiple fully articulated segments in the insertion tube, controlled by electromechanical force. During insertion, the segment is adjusted to suit the shape of the colon according to the movement of the tip, thereby reducing patient pain [25].

\subsubsection{Endoculus (University of Colorado, Boulder, CO, USA)}

Endoculus is a small tank-like robot that can navigate the colon and is capable of performing all the functions of the conventional colonoscope. The robot was propelled by four micropillared treads that functioned by dual motors (Figure 9) [32]. Endoculus robot consists of a camera, a channel for endoscopic tools, and channels for insufflation and irrigation. Endoculus robot is attached to a 2-m-long tether for power, data transmission, air, water lines, and a tool overture. Colonoscopy in in vivo preliminary tests of pigs showed successful results. Further experiments are underway by adding additional functionalities, including autonomous features and device localization. 


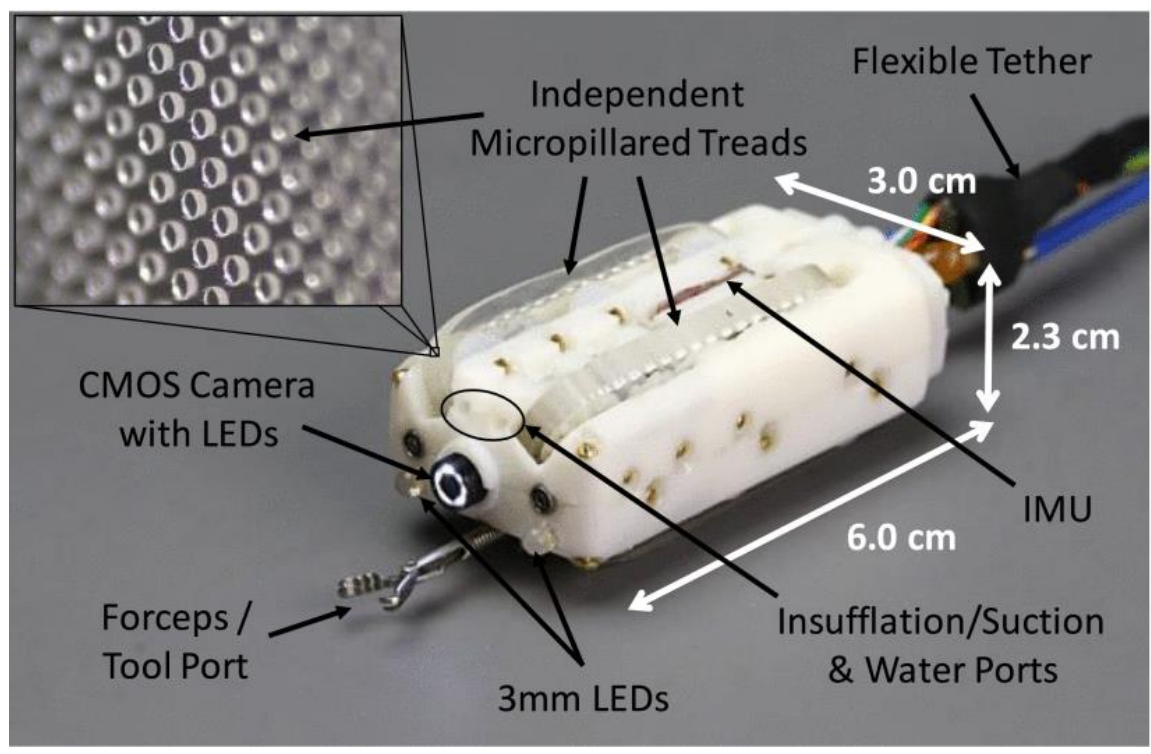

Figure 9. Endoculus (University of Colorado, Boulder, CO, USA) [32].

2.3.6. Magnetic Flexible Endoscope (Vanderbilt University, Nashville, TN, USA)

A magnetic flexible endoscope (MFE) is a soft-tethered magnetically driven colonoscope. The actuated permanent magnet (APM) external to the patient controls the magnetembedded endoscope through control software (Figure 10) [33]. The magnet-embedded endoscope includes a lighting module, a camera, a therapeutic channel, and water and air channels. It is controlled by an APM operated by a robot outside the patient. MFE has successfully demonstrated autonomous control in in vivo animal study. The system is under further development with the aim of autonomously performing endoscopic tasks [34].

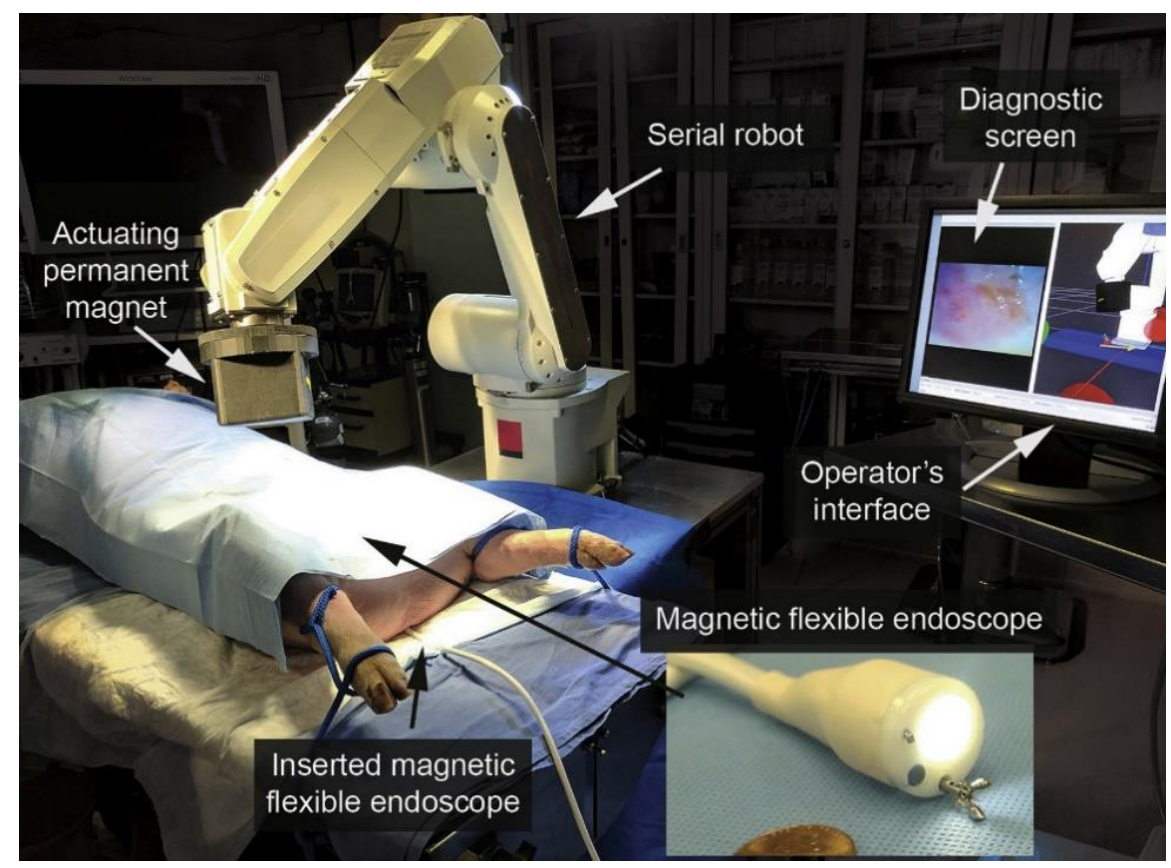

Figure 10. Magnetic flexible endoscope (Vanderbilt University, Nashville, TN, USA) [33].

\subsection{Electromechanical Control Device for Conventional Endoscope}

Devices that can be attached to a conventional colonoscope to manipulate insertion have been developed. There is a type of device that assists the endoscopist by manipulating 
the endoscope automatically when inserting the colonoscope, that is, robotic steering and automated lumen centralization (RS-ALC).

Although various endoscopic robot platforms are being studied, they are mainly designed for remote control of therapeutic tools, and the flexible manipulation of the endoscope itself still relies on conventional manual techniques. There are devices that can remotely insert endoscopes when performing therapeutic procedures with a master-slave robotic platform, such as the endoscopic operating robot (EOR) and master-slave robot by Hanyang University. These devices are being developed targeting a platform with a novel force-sensation master unit that integrates both the manipulation of the forceps and the flexible endoscope itself.

\subsubsection{Robotic Steering and Automated Lumen Centralization (RS-ALC, Enschede, The Netherlands)}

The robotic steering and automated lumen centralization system is an add-on platform that can be used for colonoscope navigation by connecting to a conventional endoscope. RS-ALC consists of a software algorithm that identifies the middle of the colonic lumen, which is the target area for the colonoscope (Figure 11) [35]. Small circles on the screen continuously represent the middle of the colonic lumen, as detected by the ALC algorithm. The endoscopist may decide to have the platform automatically steer the endoscope to follow the circle on the screen. The system is controlled by a motor module that operates the steering module attached to the endoscope via joystick. The endoscopist controls the endoscopic tip angulation by manipulating the joystick in the left hand, and the right hand controls the endoscopic shaft, similar to the conventional colonoscope. CE or FDA approval was not obtained.

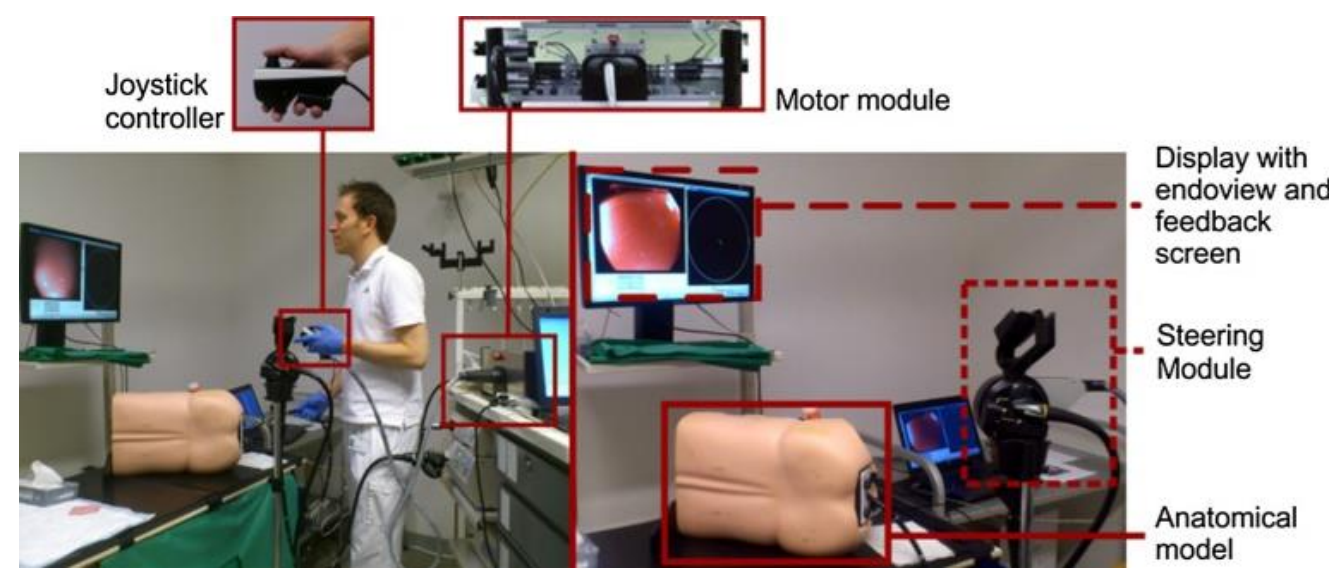

Figure 11. Robotic steering and automated lumen centralization (RS-ALC, Enschede, The Netherlands) [35].

2.4.2. Endoscopic Operation Robot (EOR; Kyushu Institute of Technology, Kitakyushu, Japan)

Endoscopic Operation Robot (EOR) was developed to replace an additional endoscopist who controls the endoscope itself in a robotic platform other than the console surgeon in the robotic endoscopic multitasking platform. The EOR is a system mounted on a conventional scope capable of manipulating it through a joystick with one hand (Figure 12) [36,37]. The master unit of the EOR Ver.3 consists of a torque sensor, a rotary motor, a rotating handle and a mini joystick. The master unit can move the flexible endoscope to four axes with one hand, enabling intuitive operation. An operating block with a rotating handle was installed on a linear motor. By operating the linear motor, the endoscope can be inserted or retracted, and the scope can be rotated with the rotating handle. It can provide complete remote control of flexible endoscopy for use in clinical practice. 


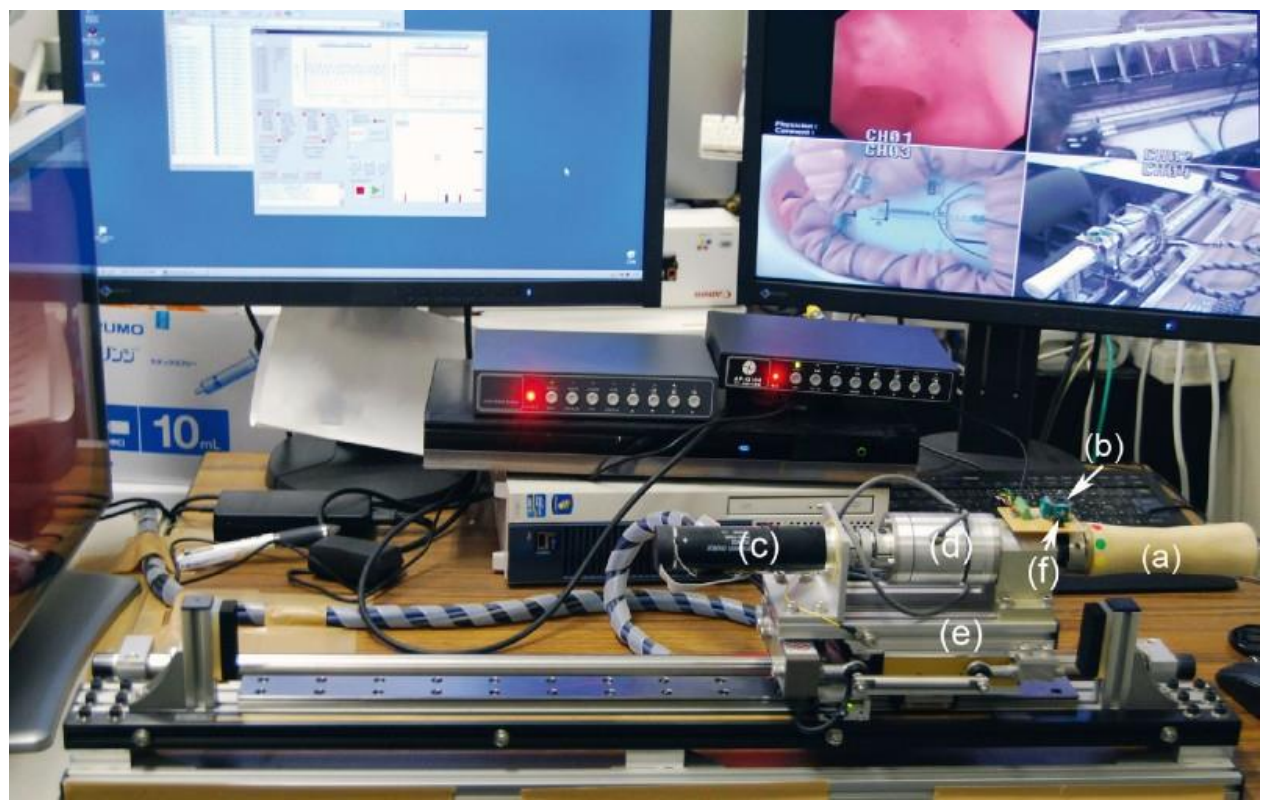

Figure 12. Components of master unit of Endoscopic Operation Robot Ver. 3 (EOR; Kyushu Institute of Technology, Kitakyushu, Japan). (a) Rotating knob, (b) mini joystick, (c) rotary motor, (d) torque sensor, (e) load cell, (f) circuit switch [37].

Recently, the same research team developed a master-slave system that allows remote manipulation of endoscopic instruments and combined it with EOR Ver.3 to create a novel endoscopic treatment robot system: the endoscopic therapeutic robot system (ETRS) [38]. Ex vivo porcine stomach ESD experiments were successfully conducted using ETRS. CE or FDA approval was not obtained.

\subsubsection{Master-Slave Robot by Hanyang University (Hanyang University, Ansan, Korea)}

This robotic colonoscopic manipulation system consists of a master controller and a slave robot (Figure 13) [39]. A two-module master device is used to control the slave device. One module is used for the insertion and twisting motion of the tube, and the other module is used for controlling the two steering motions of the endoscope tip. This master-slave robot system, which can be mounted on a conventional endoscope, can be a useful option for remote operation.
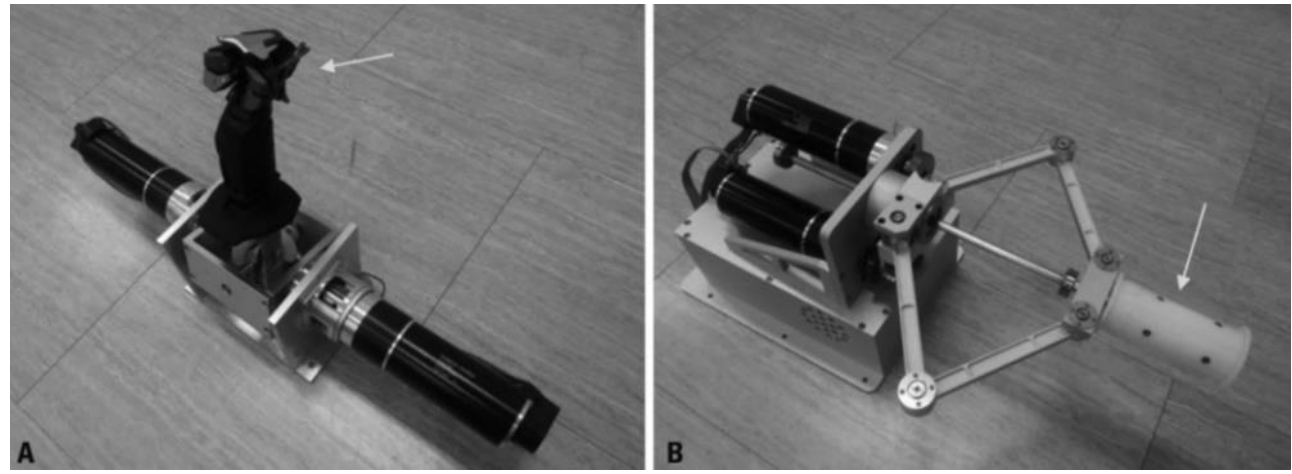

Figure 13. Master-slave robot by Hanyang University (Hanyang University, Ansan, Korea) (A) Tilting device, which is comparable to a joystick, for controlling up-down and right-left angulation of endoscopic tip. (B) Insertion and rotation device for controlling insertion, retraction, and rotation of endoscope [39]. 


\subsection{Robotics in Capsule Endoscopy}

Over the past decade, wireless capsule endoscopes (WCEs) have been developed as an interesting alternative to conventional endoscopes. WCE has the advantage of being able to gently examine the gastrointestinal tract without pain. WCE has a fatal weakness in that it is a passive device that moves only through peristalsis. Externally controlling the capsule endoscope with a magnetic field is a possible solution to this issue [40]. The external magnetic field-mediated navigation of the capsule in the gastrointestinal tract allows clinicians to potentially examine the gastrointestinal tract. As capsule endoscopes do not have the functions of water injection, suction or air inflation, the accuracy of the examination varies greatly depending on the environment in the gastrointestinal tract. In addition to adequate bowel preparation, the gastrointestinal tract should be filled with water to allow effective movement of the capsule, making exam harder for patients [41]. Magnetically controlled capsule endoscopes are being developed in the upper and lower gastrointestinal tracts and are expected to be commercialized.

\subsubsection{MCE System (Ankon Technologies Co, Ltd., Shanghai, China)}

The MCE system is a magnetically navigated capsule endoscope designed for stomach examination. When the patient swallows the magnetic capsule, an external C-arm robot rotates to manipulate the capsule inside the stomach. (Figure 14) [42]. This system consists of a magnet embedded capsule, a capsule locator, a computer workstation with ESNavi software (Ankon Technologies Co, Ltd.), a data recorder, and a C-arm type magnet robot. Images are captured and recorded at 2 frames per second with a resolution of $480 \times 480$ pixels. The C-arm type robot has 5 degrees of freedom (DOFs); 2 rotational and 3 translational DOFs. MCE can be useful in patients who cannot tolerate gastroscopy.
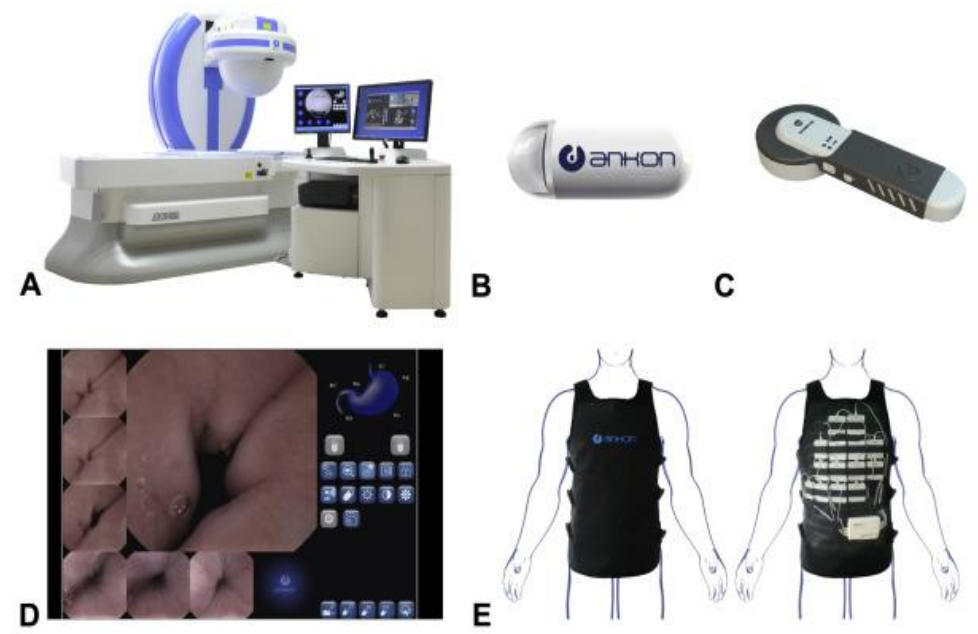

Figure 14. MCE system (Ankon Technologies Co, Ltd., Shanghai, China). (A) Guidance magnet robot and computer work station, (B) magnetic capsule endoscope, (C) capsule loca tor, (D) ESNavi software, (E) data recorder [42].

\subsubsection{Self-Propelling Capsule Endoscope (Osaka Medical College, Takatsuki, Japan)}

Self-propelling capsule endoscope (SPCE) is a capsule endoscope that can be controlled from outside the patient's body, allowing real-time observation of the entire gastrointestinal tract. The SPCE consists of a fin made of silicon resin with a micro-magnet to a commercially available PillCam ${ }^{\mathrm{TM}}$ SB2 video capsule (Covidien, Dublin, Ireland) and an external magnetic field generator (Figure 15) [43]. The magnetic field generator creates a magnetic field that shakes the fins and propels the capsule. Capsule endoscopy with SPCE in human volunteers were successfully performed. 


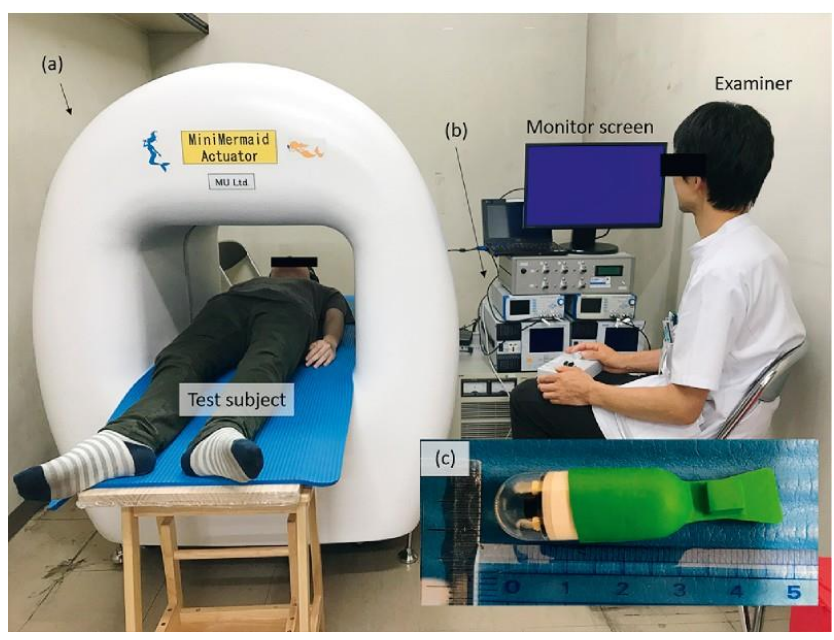

Figure 15. Self-propelling capsule endoscope (Osaka Medical College, Takatsuki, Japan). (a) The patient was examined with the self-propelling capsule endoscope (SPCE) using the New MiniMermaid System. (b) Magnetic field generator. (c) Body of the SPCE [43].

\section{Discussion and Conclusions}

Advances in endoscopic techniques have enabled clinicians to resect large polyps or early-stage cancers in the gastrointestinal tract. Various kinds of robots are being developed to provide better tissue exposure when performing technically complex endoscopic procedures, increasing the safety and efficiency. The techniques learned from robotic-assisted laparoscopic surgery and NOTES are increasingly being applied to the robotic endoscopic multitasking platforms. Robotic endoscopic multitasking platforms have presented the potential for better visualization of the surgical field, improved dexterity and improved precision of surgical manipulation. However, these systems have the disadvantages of being large, complex, and economically burdensome. From that point of view, there may be areas where simple robotic add-on devices are more appropriate. Colonoscopy is a technique that is painful for patients and difficult for practitioners. Robot-assisted colonoscopy systems have attempted automation with a softer and more flexible design, reducing bowel distension and loop formation. Various ideas have been used to promote safe and effective colon insertion, but there is still no innovative product to be widely commercialized. Although there have been improvements since the introduction of passive diagnostic capsules, robotic capsules capable of precise endoscopic maneuver are expected to have a long development period. Magnetic manipulation of the wireless capsule has shown the potential for free control of the capsule endoscope within the gastrointestinal tract.

Most of the robotic endoscopic systems presented in the review are still experimental, in the development stage, or in the process of commercialization. Some of robotic colonoscopes have been commercialized, but there are no widely used products. Many challenges still remain in the field of robotic endoscopy in gastroenterology. Adequate visualization, ease of exchangeability, haptics, accessory tools functionality, cost issues, and cleaning and reprocessing issues are the challenges ahead. The field of gastrointestinal endoscopy for both diagnostics and therapeutic intervention is progressing rapidly. Robotic endoscopy is an emerging field of research. With advances in endoscopes, robotics, and artificial intelligence, clinicians will be able to perform more complex intraluminal endoscopic procedures more safely and effectively.

Author Contributions: Writing—original draft preparation and conceptualization, S.-H.K.; resources, validation, and methodology, B.K., H.-J.C.; writing—review and editing: H.-S.C. All authors have read and agreed to the published version of the manuscript.

Funding: This work was supported by the National Research Foundation of Korea (NRF) grant funded by the Korean Government (MSIT) (Grant No. NRF-2020R1A2C4002621). This research 
was supported by a grant of Korea University Anam Hospital, Seoul, Republic of Korea (Grant No. O2106591).

Institutional Review Board Statement: Not applicable.

Informed Consent Statement: Not applicable.

Data Availability Statement: Not applicable.

Conflicts of Interest: The authors declare no conflict of interest.

\section{References}

1. Hirschowitz, B.I. Development and application of endoscopy. Gastroenterology 1993, 104, 337-342. [CrossRef]

2. Kurniawan, N.; Keuchel, M. Flexible Gastro-intestinal Endoscopy-Clinical Challenges and Technical Achievements. Comput. Struct. Biotechnol. J. 2017, 15, 168-179. [CrossRef]

3. Berbis, M.A.; Aneiros-Fernandez, J.; Mendoza Olivares, F.J.; Nava, E.; Luna, A. Role of artificial intelligence in multidisciplinary imaging diagnosis of gastrointestinal diseases. World J. Gastroenterol. 2021, 27, 4395-4412. [CrossRef] [PubMed]

4. Yamamoto, H. Endoscopic submucosal dissection-current success and future directions. Nat. Rev. Gastroenterol. Hepatol. 2012, 9, 519-529. [CrossRef]

5. Draganov, P.V.; Wang, A.Y.; Othman, M.O.; Fukami, N. AGA Institute Clinical Practice Update: Endoscopic Submucosal Dissection in the United States. Clin. Gastroenterol. Hepatol. 2019, 17, 16-25. [CrossRef]

6. Patel, N.; Seneci, C.; Yang, G.Z.; Darzi, A.; Teare, J. Flexible platforms for natural orifice transluminal and endoluminal surgery. Endosc. Int. Open 2014, 2, E117-E123. [CrossRef]

7. Wong, J.Y.Y.; Ho, K.Y. Robotics for Advanced Therapeutic Colonoscopy. Clin. Endosc. 2018, 51, 552-557. [CrossRef] [PubMed]

8. Kotzev, A.I.; Yang, D.; Draganov, P.V. How to master endoscopic submucosal dissection in the USA. Dig. Endosc. 2019, 31, 94-100. [CrossRef] [PubMed]

9. Yeung, B.P.; Chiu, P.W. Application of robotics in gastrointestinal endoscopy: A review. World J. Gastroenterol. 2016, 22, 1811-1825. [CrossRef] [PubMed]

10. Seeliger, B.; Swanstrom, L.L. Robotics in flexible endoscopy: Current status and future prospects. Curr. Opin. Gastroenterol. 2020, 36, 370-378. [CrossRef]

11. Chiu, P.W.Y.; Ho, K.Y.; Phee, S.J. Colonic endoscopic submucosal dissection using a novel robotic system (with video). Gastrointest. Endosc. 2021, 93, 1172-1177. [CrossRef]

12. Wang, Z.; Phee, S.J.; Lomanto, D.; Goel, R.; Rebala, P.; Sun, Z.L.; Trasti, S.; Reddy, N.; Wong, J.Y.; Ho, K.Y. Endoscopic submucosal dissection of gastric lesions by using a master and slave transluminal endoscopic robot: An animal survival study. Endoscopy 2012, 44, 690-694. [CrossRef] [PubMed]

13. Chiu, P.W.; Phee, S.J.; Wang, Z.; Sun, Z.; Poon, C.C.; Yamamoto, T.; Penny, I.; Wong, J.Y.; Lau, J.Y.; Ho, K.Y. Feasibility of full-thickness gastric resection using master and slave transluminal endoscopic robot and closure by Overstitch: A preclinical study. Surg. Endosc. 2014, 28, 319-324. [CrossRef]

14. Sun, Z.; Ang, R.Y.; Lim, E.W.; Wang, Z.; Ho, K.Y.; Phee, S.J. Enhancement of a master-slave robotic system for natural orifice transluminal endoscopic surgery. Ann. Acad. Med. Singap. 2011, 40, 223-230. [PubMed]

15. Phee, S.J.; Reddy, N.; Chiu, P.W.; Rebala, P.; Rao, G.V.; Wang, Z.; Sun, Z.; Wong, J.Y.; Ho, K.Y. Robot-assisted endoscopic submucosal dissection is effective in treating patients with early-stage gastric neoplasia. Clin. Gastroenterol. Hepatol. 2012, 10, 1117-1121. [CrossRef]

16. Zorn, L.; Nageotte, F.; Zanne, P.; Legner, A.; Dallemagne, B.; Marescaux, J.; de Mathelin, M. A Novel Telemanipulated Robotic Assistant for Surgical Endoscopy: Preclinical Application to ESD. IEEE Trans. Biomed. Eng. 2018, 65, 797-808. [CrossRef] [PubMed]

17. Mascagni, P.; Lim, S.G.; Fiorillo, C.; Zanne, P.; Nageotte, F.; Zorn, L.; Perretta, S.; de Mathelin, M.; Marescaux, J.; Dallemagne, B. Democratizing Endoscopic Submucosal Dissection: Single-Operator Fully Robotic Colorectal Endoscopic Submucosal Dissection in a Pig Model. Gastroenterology 2019, 156, 1569-1571.e2. [CrossRef]

18. Turiani Hourneaux de Moura, D.; Aihara, H.; Jirapinyo, P.; Farias, G.; Hathorn, K.E.; Bazarbashi, A.; Sachdev, A.; Thompson, C.C. Robot-assisted endoscopic submucosal dissection versus conventional ESD for colorectal lesions: Outcomes of a randomized pilot study in endoscopists without prior ESD experience (with video). Gastrointest. Endosc. 2019, 90, 290-298. [CrossRef]

19. Funk, E.; Goldenberg, D.; Goyal, N. Demonstration of transoral robotic supraglottic laryngectomy and total laryngectomy in cadaveric specimens using the Medrobotics Flex System. Head Neck 2017, 39, 1218-1225. [CrossRef]

20. Hwang, M.; Kwon, D.S. K-FLEX: A flexible robotic platform for scar-free endoscopic surgery. Int. J. Med. Robot. 2020, 16, e2078. [CrossRef]

21. Hwang, M.; Lee, S.W.; Park, K.C.; Sul, H.J.; Kwon, D.S. Evaluation of a robotic arm-assisted endoscope to facilitate endoscopic submucosal dissection (with video). Gastrointest. Endosc. 2020, 91, 699-706. [CrossRef] [PubMed]

22. Kim, B.G.; Choi, H.S.; Park, S.H.; Hong, J.H.; Lee, J.M.; Kim, S.H.; Chun, H.J.; Hong, D.; Keum, B. A Pilot Study of Endoscopic Submucosal Dissection Using an Endoscopic Assistive Robot in a Porcine Stomach Model. Gut. Liver 2019, 13, 402-408. [CrossRef] [PubMed] 
23. Kim, S.H.; Kim, B.G.; Choi, H.S.; Hong, D.; Jang, S.H.; Hong, K.; Choi, J.W.; Kim, S.H.; Lee, J.M.; Kim, E.S.; et al. Endoscopic submucosal dissection using a detachable assistant robot: A comparative in vivo feasibility study (with video). Surg. Endosc. 2021, 35, 5836-5841. [CrossRef]

24. Gafford, J.; Aihara, H.; Thompson, C.; Walsh, C.; Wood, R. Fuzzy-Based Feedback Control of a Tip-Mounted Module for Robot-Assisted Endoscopy. In Proceedings of the 2018 IEEE/RSJ International Conference on Intelligent Robots and Systems (IROS), Madrid, Spain, 1-5 October 2018; pp. 1-9.

25. Eickhoff, A.; van Dam, J.; Jakobs, R.; Kudis, V.; Hartmann, D.; Damian, U.; Weickert, U.; Schilling, D.; Riemann, J.F. Computerassisted colonoscopy (the NeoGuide Endoscopy System): Results of the first human clinical trial ("PACE study"). Am. J. Gastroenterol. 2007, 102, 261-266. [CrossRef]

26. Rosch, T.; Adler, A.; Pohl, H.; Wettschureck, E.; Koch, M.; Wiedenmann, B.; Hoepffner, N. A motor-driven single-use colonoscope controlled with a hand-held device: A feasibility study in volunteers. Gastrointest. Endosc. 2008, 67, 1139-1146. [CrossRef]

27. Gluck, N.; Melhem, A.; Halpern, Z.; Mergener, K.; Santo, E. A novel self-propelled disposable colonoscope is effective for colonoscopy in humans (with video). Gastrointest. Endosc. 2016, 83, 998-1004.e1. [CrossRef]

28. Shike, M.; Fireman, Z.; Eliakim, R.; Segol, O.; Sloyer, A.; Cohen, L.B.; Goldfarb-Albak, S.; Repici, A. Sightline ColonoSight system for a disposable, power-assisted, non-fiber-optic colonoscopy (with video). Gastrointest. Endosc. 2008, 68, 701-710. [CrossRef]

29. Pfeffer, J.; Grinshpon, R.; Rex, D.; Levin, B.; Rosch, T.; Arber, N.; Halpern, Z. The Aer-O-Scope: Proof of the concept of a pneumatic, skill-independent, self-propelling, self-navigating colonoscope in a pig model. Endoscopy 2006, 38, 144-148. [CrossRef] [PubMed]

30. Tumino, E.; Sacco, R.; Bertini, M.; Bertoni, M.; Parisi, G.; Capria, A. Endotics system vs colonoscopy for the detection of polyps. World J. Gastroenterol. 2010, 16, 5452-5456. [CrossRef]

31. Striegel, J.; Jakobs, R.; Van Dam, J.; Weickert, U.; Riemann, J.F.; Eickhoff, A. Determining scope position during colonoscopy without use of ionizing radiation or magnetic imaging: The enhanced mapping ability of the NeoGuide Endoscopy System. Surg. Endosc. 2011, 25, 636-640. [CrossRef]

32. Formosa, G.A.; Prendergast, J.M.; Edmundowicz, S.A.; Rentschler, M.E. Novel Optimization-Based Design and Surgical Evaluation of a Treaded Robotic Capsule Colonoscope. IEEE Trans. Robot. 2020, 36, 545-552. [CrossRef]

33. Slawinski, P.R.; Taddese, A.Z.; Musto, K.B.; Sarker, S.; Valdastri, P.; Obstein, K.L. Autonomously Controlled Magnetic Flexible Endoscope for Colon Exploration. Gastroenterology 2018, 154, 1577-1579.e1. [CrossRef]

34. Mamunes, A.P.; Campisano, F.; Martin, J.; Scaglioni, B.; Mazomenos, E.; Valdastri, P.; Obstein, K.L. Magnetic flexible endoscope for colonoscopy: An initial learning curve analysis. Endosc. Int. Open 2021, 9, E171-E180. [CrossRef] [PubMed]

35. Pullens, H.J.; van der Stap, N.; Rozeboom, E.D.; Schwartz, M.P.; van der Heijden, F.; van Oijen, M.G.; Siersema, P.D.; Broeders, I.A. Colonoscopy with robotic steering and automated lumen centralization: A feasibility study in a colon model. Endoscopy 2016, 48, 286-290. [CrossRef] [PubMed]

36. Kume, K.; Sakai, N.; Goto, T. Development of a novel endoscopic manipulation system: The Endoscopic Operation Robot ver.3. Endoscopy 2015, 47, 815-819. [CrossRef]

37. Kume, K.; Sakai, N.; Goto, T. Haptic feedback is useful in remote manipulation of flexible endoscopes. Endosc. Int. Open 2018, 6, E1134-E1139. [CrossRef]

38. Kume, K.; Sakai, N.; Ueda, T. Development of a Novel Gastrointestinal Endoscopic Robot Enabling Complete Remote Control of All Operations: Endoscopic Therapeutic Robot System (ETRS). Gastroenterol. Res. Pract. 2019, 2019, 6909547. [CrossRef]

39. Woo, J.; Choi, J.H.; Seo, J.T.; Kim, T.I.; Yi, B.J. Development of a Robotic Colonoscopic Manipulation System, Using Haptic Feedback Algorithm. Yonsei Med. J. 2017, 58, 139-143. [CrossRef] [PubMed]

40. Lien, G.S.; Wu, M.S.; Chen, C.N.; Liu, C.W.; Suk, F.M. Feasibility and safety of a novel magnetic-assisted capsule endoscope system in a preliminary examination for upper gastrointestinal tract. Surg. Endosc. 2018, 32, 1937-1944. [CrossRef]

41. Kim, J.H.; Nam, S.J. Capsule Endoscopy for Gastric Evaluation. Diagnostics 2021, 11, 1792. [CrossRef]

42. Jiang, X.; Pan, J.; Li, Z.S.; Liao, Z. Standardized examination procedure of magnetically controlled capsule endoscopy. VideoGIE 2019, 4, 239-243. [CrossRef] [PubMed]

43. Ota, K.; Kojima, Y.; Kakimoto, K.; Nouda, S.; Takeuchi, T.; Shindo, Y.; Ohtsuka, Y.; Ohtsuka, N.; Higuchi, K. Safety, efficacy, and maneuverability of a self-propelled capsule endoscope for observation of the human gastrointestinal tract. Endosc. Int. Open 2021, 9, E1391-E1396. [CrossRef] [PubMed] 